Tennakoon T.M.P.A.B. \& Dassanayake D.M.C.

Wayamba Journal of Management 12 (2)

\title{
Chinese Tourists' Food Souvenirs Selection Behaviours and Consumption Values: A Conceptual Discussion
}

\author{
T.M.P.A.B. Tennakoon ${ }^{1} \&$ D.M.C. Dassanayake ${ }^{2}$ \\ ${ }^{1,2}$ Department of Tourism \& Hospitality Management \\ Faculty of Management Studies \\ Rajarata University of Sri Lanka \\ ptennakoon@gmail.com ${ }^{1}$,cd66@students.waikato.ac.nz ${ }^{2}$
}

\begin{abstract}
Tourists frequently buy souvenirs while on vacation. Souvenir sales generate much revenue for tourist destinations, and souvenir purchasing issues cannot be ignored in a successful destination management strategy. In today's context, Chinese tourists dominate international tourism, and they tend to buy food souvenirs as gifts. Moreover, the tourist's choice of souvenirs is influenced by various factors. The theory of consumption values is one of the most precise theories explaining consumer choice behaviour. This conceptual discussion investigates the theory of consumption values' efficacy in analysing Chinese tourists' food souvenir selection by examining the values behind their selection. The review's outcome explains that the functional, social, emotional, and conditional values are in effect in choosing food gifts. However, the epistemic value remains neutral in this case. These propositions align with three fundamental recommendations of the theory of consumption values. Outcomes postulate that the theory of consumption values could explore Chinese tourists' food souvenirs choice behaviour.
\end{abstract}

Keywords-: Consumption Values, Chinese Tourists, Chinese Culture, Food Souvenirs 


\section{INTRODUCTION}

With the steady growth of China's economy, the daily consumption needs of Chinese citizens are shifting from primary living consumption to developing consumption, and tourism and leisure are becoming essential parts of people's lives (China Tourism Academy, 2018). Chinese tourists have been the major tourist markets of many countries since China's rapid economic development, and Chinese tourists tend to engage with many tourist activities on their travel or holiday.

A study with focus group interviews conducted in Hong Kong by Huang \& Hsu (2005) revealed that two out of five motivation factors were shoppingrelated, highlighting the importance of shopping for Mainland tourists. Chinese tourists spend a considerable time shopping during the travel to bring a gift back to their parents and the elders (Cai, Li, \& Knutson, 2008). Local food is very popular as gift souvenirs among Mainland China, Taiwan, Singapore, and Hong Kong (du Cros \& Jingya, 2013; Kong \& Chang, 2012; Lin, 2017). A survey focused on analysing the shopping preferences of the Chinese, and Japanese tourists who visited Taiwan indicated that they had spent most on food speciality products (Taiwan Tourism Bureau, 2014). Local food products and specialities constitute a significant amount of the total shopping expenditure of Chinese tourists who visit Taiwan, the second-largest expense (Taiwan Tourism Bureau, 2017). It is crucial to investigate what factors drive the Chinese tourists in selecting their food souvenirs.

Value-based approaches of consumer behaviour accept that the values take multiple forms, and each of the value types collectively affects different degrees of influence on the selection decision (Dassanayake, 2017; Sheth, Newman, \& Gross, 1991). Therefore, the vale-related literature provides ample evidence for the link between values and selection behaviour. Theory of consumption values (TCV) is a widely adopted theory in consumer behaviour analysis to explore consumers' choice behaviour (Sheth, Newman, \& Gross, 1991). This theory succinctly explicates how consumers choose one product among the many other alternatives using five consumption values: functional value, social value, emotional value, epistemic value, and conditional value. Although the theory has been adopted in many instances in consumer choice behaviour, there is a lack of evidence of using this theory in tourist choice behaviour, one of the compelling phenomena in the global business scenario. Moreover, despite plenty of research on Chinese tourists' choice and purchasing behaviour, the food souvenirs' choice behaviour remains to unfold. This 
paper aims at exploring the efficacy of the theory of consumption values for analysing the food souvenirs choice behaviour of the Chinese tourists.

\section{LITERATURE REVIEW \\ 2.1. Theory of consumption values}

As a valuable tool for understanding human behaviour, the value notion has grown increasingly prominent in the context of behavioural research, particularly in consumer and market research, as a result of its popularity in the field (Fleșeriu, Cosma, \& Bocăneț, 2020; Kamakura \& Novak, 1992). Theory of consumption values (TCV) developed by Sheth et al. (1991) is widely adopted for predicting the consumer choice behaviour that determines to buy or not to buy (or to use or not to use) a specific product, why one product type over another, and why consumer choose one brand over another, has been applied for more than 200 consumer choice situations (Sheth et al., 1991). In particular, the disciplines such as economics, sociology, several branches of psychology, and marketing and consumer behaviour have contributed to developing the theory of consumption values (Sheth et al., 1991).

Yang and Lin (2017) adopted the TCV to determine the influencing factors on consumer choice behaviour regarding green products and examine whether there are significant differences in consumption value and choice behaviour between consumers with different environmental concerns. Dassanayake (2017) adopted the theory of consumption values in explaining the destination choice behaviour at the various stages of the destination decision-making process. Moreover, Lee, Levy, \& Yap (2015) studied how consumption values contribute to identity and environmental attitudes using a consumer survey. Gonçalves, Lourenço, \& Silva (2016) examined whether consumption values can predict green buying behaviour using the fuzzy-set qualitative comparative analysis.

As depicted in Figure 1, TCV has identified five consumption values; functional value, social value, emotional value, epistemic value, and conditional value, influencing consumer choice behaviour (Sheth et al., 1991). The TCV is based on three fundamental propositions: consumer choosing behaviour is driven by a function of multiple consumption values, the consumption values have a differential contribution in any given consumer choosing situation, and all consumption values are independent (Sheth et al., 1991). Consequently, a choice decision is influenced by any consumption value or a combination of all the five consumption values. 


\subsubsection{Functional value}

Functional value is the primary driver that determines the choice. The perceived utility depends on an alternative's capacity for functional, utilitarian, or physical performance. Salient functional, utilitarian or physical attributes of choice are the primary determinants of the functional value (Sheth et al., 1991). The functional value results from the characteristics or attributes such as durability, reliability, and price (Ferber, 1973). For example, choosing a house might be based on functional benefits such as property quality, size, location, price and nature of the environment.

\subsubsection{Social value}

Social value is connected with the perceived utility derived from an alternative's association with one or more specific social groups. The product or service receives the social value through association with positively or negatively stereotyped demographic, socioeconomics, and cultural ethnic groups (Sheth et al., 1991). Subjective norms refer to the perceived social pressure to approve and adopt a behaviour style (Ajzen, 1991). For example, a particular wristwatch brand may be chosen more for the social image evoked than its utility. Some cultural and ethnic groups choose specific food and beverages due to pressure from their society because they follow different food faith and beliefs than perceived utilitarian value and food quality.

\subsubsection{Emotional value}

Emotional value is connected with the perceived utility derived from an alternative's ability to stimulate or provoke feelings or affective states (Sheth et al., 1991). An option receives emotional value when associated with specific feelings or when motivated by those feelings. Goods and services are generally associated with emotional responses. Emotional values are often associated with aesthetic alternatives such as religion (Sheth et al., 1991). For example, some people always choose vegetarian foods when they make choices in the supermarket since they feel that vegetarian foods protect the animals' right to live. That is their deep emotional feeling associated with emotional value.

\subsubsection{Epistemic value}

Epistemic value is connected with the perceived utility derived from an alternative's ability to generate curiosity, offers novelty and fulfil a desire for knowledge. Knowledge is a characteristic that influences all phases in the decision-making process (Laroche, Bergeron, \& BarbaroForleo, 2001). Consumers tend to choose an alternative when consumers are satisfied or bored with the current product or service or curious or desire to acquire new knowledge on something (Sheth et al., 1991). For example; Hiphop music lovers shift in buying traditional classical Indian music to learn about eastern music art while changing their way of listening to music. 


\subsubsection{Conditional value}

Conditional value is connected with the perceived utility acquired by an alternative due to a specific situation or set of circumstances facing the choice maker (Sheth et al., 1991). The alternative utility will often depend on the situation, and the existence of physical and social contingencies enhances the functional and social value of an alternative (Sheth et al., 1991). Belk (1974) defines such a situation as one in which all factors relate to a particular time and place and do not rely on personal knowledge and stimulus attributes demonstrable and systematic effects on current behaviour.

\subsubsection{Application of the theory}

The theory of consumption values has been employed in many choice situations and has manifested a significant predictive ability in each choice situation (Sheth et al., 1991). The theory has been adopted to "use versus do not use" choices about food stamps, cocaine, computer dating, and sporting events attendance: to product type choices including automobiles and to brand choices including toothpaste, aspirin, and automobile (Sheth et al., 1991). Lin and Huang (2012) adopted the TCV to determine the influence factors on consumer choice behaviour regarding green products and to examine whether there are significant differences in consumption value and choice behaviour between consumers with different outlooks on environmental concerns. Lee et al. (2015) examined how consumption value contributes to place identity, ecological attitudes, and sustainable consumption behaviour. Using a consumer survey, Gonçalves et al. (2016) examined whether consumption values can predict green buying behaviour using the fuzzy-set qualitative comparative analysis. Consumption values theory has been used to identify the determinants of the intention to continue using the SoLoMo service (Yang \& Lin, 2017). Dassanayake, Zahra, \& Cave (2015) applied the TCV to differentiate the destination choice behaviours along the different stages of the destination decision-making process. The theory was adopted by Ruangkanjanases \& Wutthisith (2018) to explore the factors influencing the intention to purchase stickers in a messaging application in Thailand.

\subsection{Souvenirs}

Souvenirs have been studied from different perspectives such as economics, functional, aesthetic and philosophical (Swanson \& Timothy, 2012). Based on the nature and areas of the study, the definition of souvenirs is varied. A souvenir means a gift, offering, or locally produced good related to a particular destination (Dougoud, 2000). A good souvenir symbolises local culture by expressing the ancestry, language, and cosmology of that culture 
(Medina, 2003). Swanson and Timothy (2012) proposed two perspectives that help comprehend the roles of souvenirs; tourist's perspective and supplier's perspective. Tourists mean souvenirs as tangible objects or intangible experiences that are symbolic reminders of an event or experience. From the supplier's perspective, souvenirs are tourist commodities found in souvenir shops and handicraft markets. Gordon (1986) first constructs a typology for souvenirs identifying five categories; pictorial images (e.g., picture-postcard), piece of the rock (e.g., pinecones, seashell, and rocks), symbols of a destination (e.g., miniature Eiffel Tower), markers (e.g., T-shirts), and local products (e.g., foods and clothing). Swanson and Timothy (2012) proposed four categories of souvenirs; totality souvenirs (e.g., logoed objects that represents visitors' feeling about the destination), linking souvenirs (e.g., kitchenware that can maintain a link to the destination when tourist return home), pilgrimage souvenirs (e.g., a model cross from Jerusalem), and life souvenirs (e.g., food products filled with nostalgia feelings). Scholars and authors have explored that souvenirs possess different attributes. Snepenger, Murphy, O'Connell, and Gregg (2003) identify the following decisive factors which are considered as essential attributes by tourists in purchasing souvenirs, such as convenience and practicality- including portability, ease of cleaning, practicality and price, aesthetics, such as colour, design, and display and uniqueness- special, limited and innovation meanings. Swanson and Horridge (2006) explicate three broad categories of products attributes for souvenirs: care and travel factors (ease of care or cleaning, price, usefulness, whether the item is a good gift made in the place visited), aesthetic selection factors (appealing colour, appealing design, wearability and whether the item can display in the home), unique selection factors ( made by well-known local craftsperson/ artisan, unique, one of a kind or limited edition pieces, highquality artistry, new, innovative, or a clever idea). $\mathrm{Hu}$ and $\mathrm{Yu}$ (2007) classified the attributes of souvenirs into two categories; craftsmanship (evaluation of artistry often involving details such as appliques, finished edges, fringes, thread choice, nicely finished wrong side and neat machine stitching), and sensuous appreciation (the intrinsic beauty of a craft's colour, design or artistry, with other symbolism unnecessary for the item to be meaningful). In recent years we can find broad views of souvenir attributes. Paraskevaidis and Andriotis (2015) explored the souvenirs' use-value, exchange value, sign value, and spiritual value based on sociological aspects.

There are many motivations for purchasing souvenirs. Kim and Littrell (2001) stated that two motives of tourists for buying 
souvenirs; keep souvenirs as proof of their journey themselves and give souvenirs as a gift to others to maintain the social relationships. The motivation for purchasing gift-giving souvenirs is considered to maintain reciprocal obligations and comply with the social norms (Kim \& Littrell, 2001; Park, 2000). JansenVerbeke (1991) divided souvenir purchasing motivations into three categories; economic reasons such as cost-saving by bargaining or taking advantage of the favourable exchange rate, psychological effects on identifying the destination, and strengthening social ties. Roles of souvenirs as gifts, aid memoirs, and evidence identified by Wilkins (2011) have been considered the motivations for purchasing souvenirs by tourists in his study.

\subsection{Food souvenir}

Food specialities are purchased mainly by tourists as souvenirs during their travel (Lin \& Mao, 2015). Food and beverages products, including sweets, alcohol, spices, and tea, are considered popular food souvenirs among cultural tourists (Buczkowska, 2014). Food is an effective medium of symbolising local culture and connecting tourists to a destination's landscape and the way of life of the host community (Harrington \& Ottenbacher, 2010). Food speciality is considered one kind of souvenirs, primarily refers to food purchased by tourists in a specific tourist destination. Food speciality has a unique meaning linked with a particular culture and location.

On the other hand, a food speciality can be considered a tangible means of capturing the specific nature of a particular region (Lin \& Mao, 2015). Tourists purchase food souvenirs for different purposes, sometimes enjoy the savour of the food themselves, or mentally imagine its identity (Lin \& Mao, 2015). We can see some tourist destinations produce food specialities that best symbolise and represent the unique identity. For example, tourist purchases Ceylon tea leaves from Sri Lanka, Maple syrup from Canada, Salmon from Norway, Burgundy wine from France, black caviar from Russia, and chocolate from Switzerland. Tourists will have an opportunity to evoke the natural feeling of taste and smell of the place they have visited as they enjoy the food souvenirs (Lin \& Mao, 2015). For example, a tourist who is back from Mexico loves to bring a bottle of premium Tequila as a souvenir. As he enjoyed the drink, the bottle of tequila could sense the fantastic flavour and feelings from his trip. In Japanese, souvenirs are called "omiyage". Most of the tourist destinations in Japan offer representative food, such as candies, wine, and tea. When Japanese tourists travel in the country or abroad, they must buy omiyage for their family members, friends, and coworkers. Japanese always maintain solid relationships and show reciprocity (Witkowski \& 
Yamamoto, 1991). Tourists bring home food speciality from specific destinations as food souvenirs for themselves or others (Table 1) (Lin \& Mao, 2015).

\subsection{Chinese tourists shopping behaviour}

Researchers have revealed that Chinese culture is primarily collectivistic, characterising groups and authority, not individuals (Hofstede \& Bond, 1984; Hsu, 1985; Stening, Everett, \& McDonald, 1987). Interpersonal relationships and social orientation among the Chinese people stem from the Chinese cultural values derived from the teaching of Confucius, whose doctrine is still the fundamental pillars of Chinese life today (Mok \& DeFranco, 2000). Dominant Chinese cultural values largely shape the consumption patterns, preferences, and expectations in international travel activities; shopping, choosing destinations, food preferences and travel types (Mok \& DeFranco, 2000). The souvenir purchasing behaviour of the tourists is primarily influenced by the cultural background of the tourists (Lee, Kim, Seock, \& Cho, 2009; Park, 2000). It is a norm to purchase a gift for friends and relatives by the tourists from oriental cultures when they return home after they travel abroad, which is considered an influential travel motivation for going abroad (Xu \& McGehee, 2012). A focus group interview conducted in Hong Kong by Huang \& Hsu (2005) revealed that two out of five motivation factors were shopping-related, highlighting the importance of shopping for Mainland tourists. Chinese tourists spend a long time travelling for shopping to bring a gift back to their parents and the elders (Cai et al., 2008). The study (Hsu, Kang, \& Lam, 2006) has manifested that the travel-related decision making of the Chinese tourists is affected mainly by relatives, friends, and other reference groups. It is an obligatory act of buying a gift by Chinese tourists for seniors, children, and friends during overseas travel, appreciating traditional collectivist values such as family duty and caring for children (Li, Lai, Harrill, Kline, \& Wang, 2011). Tourists from China, Japan, and Korea engage in shopping during their holidays for themselves and their extended families and acquaintances. Researchers have discerned that the shopping behaviour of tourists from Eastern culture is varied from the western travellers, emphasising the cultural values and norms (Guo, Seongseop Kim, \& Timothy, 2007; Timothy, 2005). Chinese people hold two meanings for souvenirs, which classify souvenirs, based on the values and types; one category represents objects or items that possess a commemorative value, called 'Ji- nian-pin', other category includes gift, called 'ban-shou-li' the term 'ban-shou-li' generally covers desserts, wines, and or tea (Lin, 2017) 


\subsection{Criticism on the theory and literature}

Despite existing group choices or group decision making in the realworld scenario, the TCV can only be applied to individual decisionmaking situations (Sheth et al., 1991). This fact is one of the criticisms which lowers the ability of predictive validity of the theory. The theory of consumption values is always based on the systematic decisionmaking situation (Sheth et al., 1991). However, random or impulse buying choices take place in our routine life. The theory has ignored impulsive or random consumers' buying choices, which marketers and the current business world heavily exploit. During the impulse or stochastic choice situation, the consumer never assesses the five values introduced by the theory. Consumer buying decisions are not always a rational decisionmaking process. In the real world, consumers are unable to disregard some choice situations. There are some mandatory or involuntarily choices. Nevertheless, the theory of consumption values has considered only voluntary decision making (Sheth et al., 1991).

Technological advancement has replaced the typology of pictorial images introduced by Gordon (1986). To remind the journey and its experiences, tourists heavily use virtual photos and social media. Other social media has opened avenues to share these experiences with a significant number of friends and relatives associated with tourists. Linking souvenirs identified by Swanson \& Timothy (2012) seemed unrealistic in the global market. Like China and Taiwan, some countries have acquired mass production of some products such as cutlery, crockery, and small electronic appliances. They produced these products, which are considered souvenirs by the tourists, and export to different tourist destinations in different places in the world. Although tourists purchase this product believing as linking souvenirs, they would disappoint as they knew the country of origin of those products. Researchers have identified a wide array of souvenirs attributes that are expected to be assessed by the tourists before souvenirs are purchased (Graburn, 1979; Hu \& Yu, 2007; Paraskevaidis \& Andriotis, 2015; Pysarchik, 1989; Snepenger et al., 2003; Swanson \& Horridge, 2006; Swanson \& Timothy, 2012). However, the attributes they identified are relatively generalised, which hardly consider the situational factors tourists encounter. For example, some tourists would purchase jewellery or precious stone products as souvenirs for a special moment of life during the travel or a holiday despite the price. Reasonable price, considered an attribute of souvenirs by most researchers, does not apply to tourist souvenir purchasing behaviours. 
3. CASE STUDY -

SOUVENIRS

PURCHASING

BEHAVIOUR OF THE CHINESE TOURISTS IN TAIWAN

This case study was extracted from the study conducted by Lin (2017), in which the Chinese tourists' food souvenir purchasing behaviour is elaborated and analysed. That particular study's findings were based on data gathered from 318 Chinese tourists by distributing a questionnaire in two locations in Taiwan; National Chiang Kaishek Memorial Hall in Taipei and Ruifeng Night Market in Kaohsiung city.

As shown in table 2, $43.2 \%$ of the tourists have purchased pastries, cookies, and confections as food souvenirs recording the highest percentage, followed by the beverage categories representing $25.7 \%$. Reasons for buying Pastries, cookies, and confections are relatively cheap, lightweight, portable, suitable for young and old recipients, and easy to share. Wines and tea are of high value for Chinese consumers. Wine has always been a preferred food gift among Chinese people because it is believed to symbolise luxury. When they purchase wine as a gift, they prefer foreign wines.

Table 3 depicts that the primary purpose of buying food souvenirs by the Chinese tourists is for giving a gift for family, indicating a $32.6 \%$, followed by the friend category showing $24.4 \%$. $23.5 \%$ of the tourists purchase food souvenirs for themselves as evidence of the journey and memories of the trip.

Three main motivations, as a gift, memory, and evidence, have been found behind buying food souvenirs by the Chinese outbound tourist. Each stimulus consists of some dimensions which imply the various reasons for buying food souvenirs. In analysing motivations for purchasing souvenirs by the Chinese tourists, data reveal that the strongest motive is acquiring gifts, followed by the motivations for evidence and memory aids. They expect to exchange these gift food souvenirs during the main festival of the Chinese culture, such as the Lunar new year, the dragon boat festival, and the midAutumn festival

The majority of the respondents have spent NTD 501-1000 buying souvenirs $(34.9 \%)$, followed by the NTD1001-3000 recording $31.4 \%$ of the total respondents.

As can be seen, $27.5 \%$ of Chinese tourists have purchased food souvenirs from different tourist destinations in Taiwan, followed by souvenirs stores and food speciality stores. $15.3 \%$ of the tourists have purchased food souvenirs from airport and train stations. They prefer to interact with the culture, local events, history, and environmental conditions while travelling to different tourist destinations where they often purchase food souvenirs. Tourists are provided to the facility to visit local food 
factories located in tourists' destinations in Taiwan.

\section{DISCUSSION}

This section of the paper explores the influence of each consumption value explained in the theory of consumption values in choosing food souvenirs by Chinese tourists to identify the reasons for this specific choice behaviour. The authors and researchers have proposed different souvenirs considering the key characteristics and attributes (Gordon, 1986; Swanson \& Timothy, 2012). Four souvenir types, such as totality souvenirs, linking souvenirs, pilgrimage souvenirs, and life souvenirs proposed by Swanson \& Timothy (2012), have been adopted in this paper to analyse the food souvenir choice behaviour of the Chinese outbound tourists. Literature and case study postulate that Chinese tourists dispose of purchasing food souvenirs, which is coming under the life souvenir category, over other souvenirs. These tourists believe that food souvenir is the best alternative over different souvenir types that fulfil the souvenirs' role.

\subsection{Functional value and food souvenir choice behaviour}

The functional value is derived from its characteristics or attributes such as; reliability, durability, and price (Ferber, 1973). According to the literature review, food souvenirs possess vital attributes derived from sensory, utility, and symbolism (Lin \& Mao, 2015). Despite little literature in this area, the case study adopted in this study has proved that Chinese tourists consider portable, convenient and practical, and reasonable price as the main factors in choosing food souvenirs in Taiwan during their travel, which are considered the quality attribute of food souvenirs. These attributes can be identified as the salient physical attributes Chinese tourists assess when choosing food souvenirs. During their holiday in Taiwan, they have purchased pastries, cookies, and confections for young and old recipients. Chinese tourists prefer buying foreign wines as food souvenirs for a gift (wine from France, Australia, and Italy). The wine source country emphasises the quality and value symbolised by the product. These food and beverage souvenirs have acquired higher functional values over other souvenirs due to possessing salient attributes expected by the Chinese tourist during their holiday.

\subsection{Social value and food souvenir choice behaviour}

Functions of souvenirs as a gift, as a memory, and as evidence of journey are considered motivations for purchasing souvenirs (Wilkins, 2011). Purchasing gifts for relatives, friends or colleagues during trips has become a habit or is an obligation for Chinese people ( $\mathrm{Li}$ et al., 2011). In analysing the motivations of Chinese tourists to purchase food souvenirs during their journey in Taiwan, it proves that gift-giving is a more apparent 
purpose than others. The strong relationship between gift-giving and food souvenirs' motivation stems from Chinese social values. Food sharing and gift-giving culture may influence food souvenirs choosing behaviour when they travel; they are inspired to select gift food as souvenirs to family and friends to express love and concern or thank colleagues for tolerating possibly increased workloads and inconveniences caused by the giver's travel abroad. On the other hand, Chinese tourists often choose festive food products as food souvenirs for relatives and friends to exchange during the main Chinese festivals; the lunar New Year, the dragon boat festival, and the mid-Autumn festival. Food souvenirs acquire a tremendous social value over other souvenirs derived from the Chinese people's solid and dominant cultural norms, values, and customs.

\subsection{Emotional value and food souvenir choice behaviour}

As an aid of memory and evidence, two motives are associated with the tourists' deep emotions and intense feelings who purchased souvenirs during their travel. It has been postulated that food souvenirs are effective mediums of symbolising local culture and connecting tourists to a destination's landscape and the way of life of the host community. It contends that tourists will have an opportunity to evoke the natural taste and smell of the place they visited as they enjoy the food souvenirs. The symbolic attributes of the Chinese tourists' food souvenirs purchased from Taiwan evoke the emotional attachment to different places, events, lives and cultural history, environmental conditions, and production processes. Food souvenirs choice of the Chinese tourist visited Taiwan is related to the feeling of authenticity created by the purchasing environment or context. Compared with a food souvenir at an airport, bus station or supermarket, a food souvenir at tourist destinations is more connected to and compatible with these attractions, thus enhancing the perception of the food's authenticity. Case study and literature show that it acquires a higher emotional value in choosing food souvenirs by the Chinese outbound tourists during their holiday or travel.

\subsection{Conditional value and food souvenir choice behaviour}

Travelling and spending a holiday in tourist destinations provides travellers and holidaymakers with opportunities for shopping and purchasing a wide choice of unique and authentic products at reasonable prices. The case study proved that the primary motivation of the Chinese tourists who visited Taiwan is to purchase food speciality as souvenirs for family and friends. Travelling and spending a holiday in tourist destinations of Chinese tourists offer a higher conditional value in choosing gift food souvenirs over other types of souvenirs. Further, the conditional value enhances the social and functional values of the 
Chines tourists' food souvenir choice behaviour, providing an opportunity to select quality gift food souvenirs that fulfil the expectations of family members, relatives, friends, and acquaintances.

\subsection{Epistemic value and food souvenir choice behaviour}

Even though the epistemic value affects most consumers' choice behaviour, existing literature and the case study information have not provided enough evidence to explore the effect of epistemic value on Chinese tourists' food souvenirs' choice behaviour. As a result, it can be stated that epistemic value remains neutral in this phenomenon.

\section{CONCLUSION}

The theory of consumption values that have been barely adopted in analysing tourist choice behaviour was used to explore Chinese tourists' food souvenir choice behaviour. Literature in this area and case-study used in the paper are underpinning to study the Chinese tourists' food souvenir choice behaviour, providing evidence of how four consumption values affect the food souvenir choice behaviour. At the same time, available literature and the case study would not support identifying the effect of epistemic value on food souvenir choice behaviour. Food souvenirs seem to acquire a more significant social value than other souvenirs among Chinese tourists. Food souvenirs have been identified as the best medium of giving gifts of the Chinese culture than other types of souvenirs. Gift-giving has become an obligatory norm among Chinese tourists, derived from the collectivistic Chinese culture. Food souvenirs have acquired an emotional value over other souvenirs because Chinese tourists believe that food souvenirs could play a remarkable role in evoking memories on their journey to different places as they enjoy the food. The emotional value of food souvenirs is derived from purchasing food souvenirs; as a memory aid and as evidence of the journey. It could be stated that food souvenirs acquire a comparatively lower emotional value than the social value in choosing food souvenirs by Chinese tourists. Food souvenirs acquire functional values over others because they possess salient attributes of portable, convenience and practical, and reasonable price, assessed by Chinese tourists in choosing food souvenirs. Spending holidays as travellers make the opportunity to purchase food souvenirs for Chinese tourists. They have an excellent opportunity to choose the best food souvenirs over other types of souvenirs. As a result, food souvenirs acquire a conditional value in choosing them by the Chinese tourists. It could be stated that food souvenirs acquire comparatively lower functional and conditional value in choosing food souvenirs by the Chinese tourists. The above conclusions aligned with fundamental propositions of the 
theory of consumption values, such as consumer choice is a function of multiple consumption values. The consumption values make differential contributions in any given choice situation, and the consumption values are independent (Dassanayake \& Zahra, 2013; Sheth et al., 1991).

This paper adopted the theory of consumption values to explore the predictive validity of the theory and identify the specific reasons for the food souvenir choice of Chinese tourists. However, future empirical research and conceptual works can address the untouched areas by this paper. Further, this paper focused only on the purchasing behaviour of Chinese tourists, whose purchasing behaviour is rather varied from the western tourists. Analysing the choice behaviour of the tourists in western culture by using the theory would help us assess the predictive validity of this theory in the tourism field. Even though the paper explains the effect of each consumption value on food souvenir choice behaviour in the paper, it is essential to quantify the effect of each consumption value to take an overarching view on this behaviour of the Chinese tourists. Finally, there is a little literature on tourists' food souvenirs and food souvenirs purchasing behaviour. Conducting ground-level research would allow us to flesh out the actual situation of these concepts.

\section{APPENDIX}

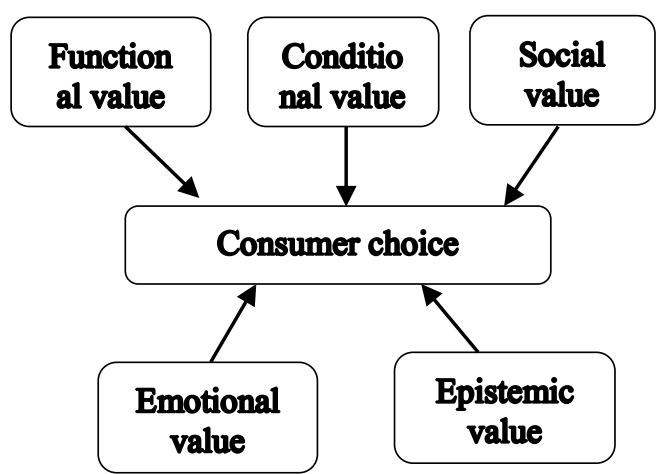

Figure 1: Model of the theory of consumption values

Source: (Sheth et al., 1991) 
Tennakoon T.M.P.A.B. \& Dassanayake D.M.C.

Wayamba Journal of Management 12 (2)

\begin{tabular}{|c|c|}
\hline \multicolumn{2}{c|}{ Table 1: Dimensions and attributes of food speciality souvenirs } \\
\hline Dimension & Attributes \\
\hline \multirow{3}{*}{ Sensory } & Flavour versatility \\
& Texture modification \\
& Procedural innovations \\
& Visual appreciation \\
\hline Utility & Natural and organic \\
& Environmental sustainability \\
& Healthy \\
& Convenience \\
& High quality \\
& Market feasibility \\
\hline \multirow{3}{*}{ Symbol } & Authentic and indigenous \\
& Traditional \\
& Craftsmanship \\
& Storytelling and reminiscent \\
& Modern and fun \\
\hline
\end{tabular}

Source (Lin \& Mao, 2015)

Table 2: Types of food souvenirs bought during the holiday

\begin{tabular}{|c|c|}
\hline Type of food souvenir & Percentage \% \\
\hline Pastries, cookies, and confections & 43.2 \\
\hline Proceed meat, canned food, and cheese & 15.7 \\
\hline Herbs and sauces (cooking ingredients) & 11.7 \\
\hline Beverage (tea, coffee, wine) & 25.7 \\
\hline Other & 3.6 \\
\hline
\end{tabular}

Source (Lin, 2017)

Table 3: Purpose of buying food souvenirs

Source (Lin, 2017)

\begin{tabular}{|c|c|}
\hline Purpose & Percentage \% \\
\hline Myself & 23.5 \\
\hline Family & 32.6 \\
\hline Friends & 24.4 \\
\hline Colleagues & 14.3 \\
\hline Supervisors and boss & 5.1 \\
\hline Others & 0.1 \\
\hline
\end{tabular}

Table 4: Amount spent on food souvenirs

\begin{tabular}{|c|c|}
\hline Amount in NTD & Percentage \% \\
\hline Bellow NTD 500 & 16 \\
\hline NTD 501-1000 & 34.9 \\
\hline NTD 1001-3000 & 34.4 \\
\hline NTD 3001-5000 & 7.9 \\
\hline Above NTD - 5001 & 9.4 \\
\hline
\end{tabular}

*NTD - new Taiwan Dollar

Source (Lin, 2017) 
Tennakoon T.M.P.A.B. \& Dassanayake D.M.C.

Wayamba Journal of Management 12 (2)

Table 5: Locations of food souvenirs purchased

\begin{tabular}{|c|c|}
\hline Locations & Percentage \% \\
\hline Tourists destinations & 27.5 \\
\hline Souvenir stores & 14.6 \\
\hline Food speciality stores & 19.2 \\
\hline Convenient stores and supermarket & 11.3 \\
\hline Airport and train stations & 15.3 \\
\hline Food vendor or traditional market & 11.3 \\
\hline
\end{tabular}

Source (Lin, 2017)

\section{REFERENCES}

Ajzen, I. (1991). The theory of planned behavior. Organisational behavior and human decision processes, 50(2), 179211.

Belk, R. W. (1974). An exploratory assessment of situational effects in buyer behavior. Journal of marketing research, 156-163.

Buczkowska, K. (2014). Local food and beverage products as important tourist souvenirs. Turystyka Kulturowa, 1(2014), 47-58.

Cai, L. A., Li, M., \& Knutson, B. J. (2008). Research on China outbound market: A meta-review. Journal of Hospitality \& Leisure Marketing, 16(1-2), 5-20.

China Tourism Academy. (2018).

The changing chinese tourists; new needs and new expectations. Retrieved from http://eng.ctaweb.org/htm 1/2018-3/2018-3-7-10-4222287.html
Dassanayake, D. M. C. (2017). The role of values in destination decisionmaking: The Indian travel market (Doctoral dissertation, University of Waikato).

Dassanayake, D. M. C., \& Zahra, A. (2013). Role of consumption values in destination decisionmaking: A qualitative analysis. Paper presented at the 17th Waikato Management School Student Research Conference, Waikato Management School.

Dassanayake, C., Zahra, A., \& Cave, J. (2015). The role of consumption values in the destination decision-making process. CAUTHE 2015: Rising Tides and Sea Changes: Adaptation and Innovation in Tourism and Hospitality, 123134

Dougoud, R. C. (2000). Souvenirs from Kambot (Papua New Guinea): The sacred search for authenticity. Souvenirs: The Material 
Culture of Tourism, 223237.

du Cros, H., \& Jingya, L. (2013). Chinese youth tourists views on local culture. Tourism Planning \& Development, 10(2), 187204.

Ferber, R. (1973). Consumer economics, a survey. Journal of Economic Literature, 11(4), 13031342.

Fleșeriu, C., Cosma, S. A., \& Bocăneț, V. (2020). Values and planned behaviour of the romanian organic food consumer. Sustainability, 12(5), 1722.

Gonçalves, H. M., Lourenço, T. F., \& Silva, G. M. (2016). Green buying behavior and the theory of consumption values: A fuzzy-set approach [Article]. Journal of Business Research, 69(4), 1484-1491.

doi:10.1016/j.jbusres.201 5.10.129

Gordon, B. (1986). The Souvenir: Messenger of the Extraordinary [Article]. The Journal of Popular Culture, 20(3), 135-146. doi:10.1111/j.00223840.1986.2003_135.x

Graburn, N. H. (1979). Ethnic and tourist arts: Cultural expressions from the fourth world: Univ of California Press.

Guo, Y., Seongseop Kim, S., \& Timothy, D. J. (2007). Development characteristics and implications of mainland Chinese outbound tourism. Asia Pacific Journal of Tourism Research, 12(4), 313-332. Harrington, R. J., \& Ottenbacher, M. C. (2010). Culinary tourism-A case study of the gastronomic capital. Journal of Culinary Science \& Technology, 8(1), 14-32.

Hofstede, G., \& Bond, M. H. (1984). Hofstede's culture dimensions: An independent validation using Rokeach's value survey. Journal of crosscultural psychology, 15(4), 417-433.

Hsu, C. H., Kang, S. K., \& Lam, T. (2006). Reference group influences among Chinese travelers. Journal of Travel Research, 44(4), 474-484.

Hsu, F. L. (1985). The self in cross-cultural perspective. Culture and self: Asian and Western perspectives, 24, 55.

Hu, B., \& Yu, H. (2007). Segmentation by craft selection criteria and shopping involvement. Tourism Management, 28(4), 1079-1092.

Huang, S., \& Hsu, C. H. (2005). Mainland Chinese residents' perceptions and motivations of visiting Hong Kong: Evidence from focus group interviews. Asia Pacific 


Journal of Tourism
Research, 10(2), 191-205.
Jansen-Verbeke, M. (1991).
Leisure shopping: A
magic concept for the
tourism randustry?
Tourism Management,
12(1), $9-14$.
doi:https://doi.org/10.101
6/0261-5177(91)90024-N

Kamakura, W. A., \& Novak, T. P. (1992). Value-system segmentation: Exploring the meaning of LOV. Journal of consumer research, 19(1), 119-132.

Kim, S., \& Littrell, M. A. (2001). Souvenir buying intentions for self versus others. Annals of tourism research, 28(3), 638-657.

Kong, W. H., \& Chang, T.-Z. (2012). The role of souvenir shopping in a diversified Macau destination portfolio. Journal of Hospitality Marketing \& Management, 21(4), 357373.

Laroche, M., Bergeron, J., \& Barbaro-Forleo, G. (2001). Targeting consumers who are willing to pay more for environmentally friendly products. Journal of consumer marketing, 18(6), 503-520.

Lee, C. K. C., Levy, D. S., \& Yap, C. S. F. (2015). How does the theory of consumption values contribute to place identity and sustainable consumption? [Article].
International Journal of Consumer Studies, 39(6), 597-607. doi:10.1111/ijcs.12231

Lee, Y., Kim, S., Seock, Y.-K., \& Cho, Y. (2009). Tourists' attitudes towards textiles and apparel-related cultural products: A cross-cultural marketing study. Tourism Management, 30(5), 724732.

Li, X., Lai, C., Harrill, R., Kline, S., \& Wang, L. (2011). When east meets west: An exploratory study on Chinese outbound tourists' travel expectations. Tourism Management, 32(4), 741749. doi:https://doi.org/10.101 6/j.tourman.2010.06.009

Lin, L. (2017). Food souvenirs as gifts: tourist perspectives and their motivational basis in Chinese culture [Article]. Journal of Tourism and Cultural Change, 15(5), 439-454. doi:10.1080/14766825.20 16.1170841

Lin, L., \& Mao, P.-C. (2015). Food for memories and culture - A content analysis study of food specialties and souvenirs. Journal of Hospitality and Tourism Management, 22, 19-29. doi:https://doi.org/10.101 6/j.jhtm.2014.12.001

Lin, P. C., \& Huang, Y. H. (2012). The influence factors on choice behavior regarding 


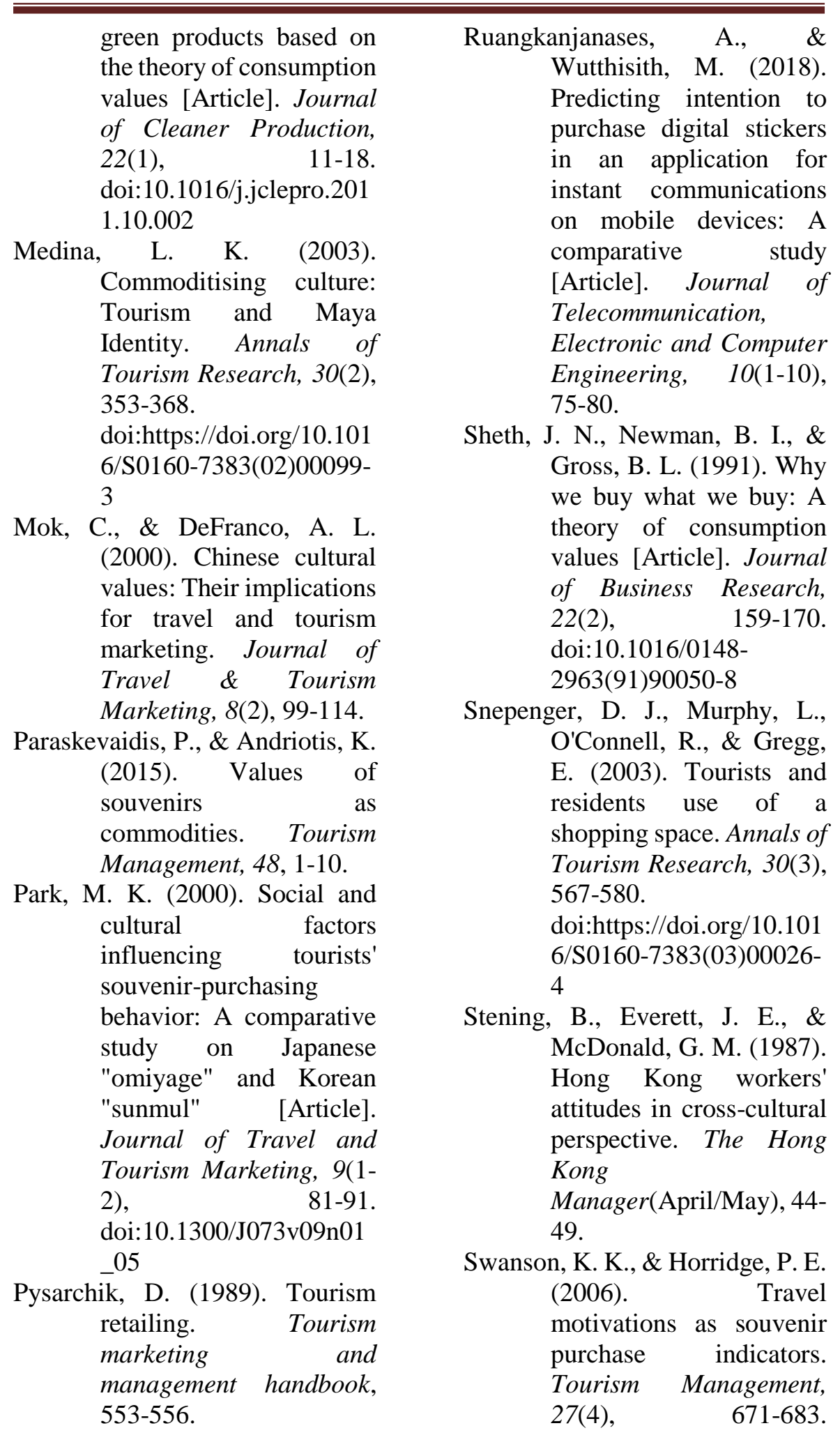


doi:https://doi.org/10.101

6/j.tourman.2005.03.001

Swanson, K. K., \& Timothy, D. J. (2012). Souvenirs: Icons of meaning, commercialisation and commoditisation.

Tourism Management, 33(3), 489-499. doi:https://doi.org/10.101 6/j.tourman.2011.10.007

Taiwan Tourism Bureau. (2014). Annual survey report on visitors expenditure and trends in Taiwan

Taiwan Tourism Bureau. (2017). Annual survey report on visitors expenditure and trends in Taiwan. Retrieved from https://admin.taiwan.net.t w/statistics/market.aspx.

Timothy, D. J. (2005). Shopping tourism, retailing and leisure: Channel View Publications.

Wilkins, H. (2011). Souvenirs: What and why we buy. Journal of Travel Research, 50(3), 239-247.

Witkowski, T. H., \& Yamamoto, Y. (1991). Omiyage gift purchasing by Japanese travelers the U.S. Advances in Consumer Research, 18(1), 123-128.

Xu, Y., \& McGehee, N. G. (2012). Shopping behavior of Chinese tourists visiting the United States: Letting the shoppers do the talking. Tourism Management, 33(2), 427430. doi:https://doi.org/10.101 6/j.tourman.2011.05.003

Yang, H. L., \& Lin, R. X. (2017). Determinants of the intention to continue use of SoLoMo services: Consumption values and the moderating effects of overloads [Article]. Computers in Human Behavior, 73, 583-595. doi:10.1016/j.chb.2017.0 4.018 